\title{
Núcleo de Pesquisa em Suínos como Centro Formador de Recursos Humanos para a Suinocultura do Futuro
}

\author{
Diego Feitosa Leal, Bruno Bracco Donatelli Muro, Simone Maria Massami Kitamura Martins, \\ Andrea Micke Moreno, Aníbal Sant'Anna Moretti, André Furugen Cesar de Andrade*
}

Swine Research Center - Faculdade de Medicina Veterinária e Zootecnia da Universidade de São Paulo

* Autor para correspondência: andrefc@usp.br

\section{RESUMO}

A suinocultura se destaca dentre as demais atividades produtivas pelo uso massivo de ferramentas tecnológicas, objetivando produzir em maior volume, de forma mais eficiente e sustentável. Nessa conjuntura, a suinocultura brasileira ocupa lugar destacado entre os principais países produtores, ocupando o quarto posto no ranking de produção e exportação de carne suína; dessa forma, fica clara a importância da atividade suinícola como grande geradora de divisas para o país. Assim, faz-se imprescindível a formação de recursos humanos altamente capacitados para que possam militar nesta seara com assertividade, impulsionando cada vez mais a produção de suínos e, em consequência, o desenvolvimento do país. Tendo em vista tal demanda, surgiu o Núcleo de Pesquisa em Suínos, resultado da união de forças entre o Laboratório de Pesquisa em Suínos, o Laboratório de Andrologia e Tecnologia de Embriões Suínos e o Laboratório de Sanidade Suína e Virologia, com o intuito de que os alunos da graduação, e não somente os da pós-graduação, como antes ocorria, pudessem entrar em contato com um cenário fidedigno da produção de suínos. Hoje, os alunos que estão ainda na graduação podem participar de atividades similares àquelas que são realizadas em uma granja comercial de suínos, com a vantagem de estarem sempre monitorados por professores e alunos de pós-graduação.

Palavras-Chave: Suinocultura; Formação de Recursos Humanos; Interdisciplinaridade.

\begin{abstract}
Pig production has gained worldwide notoriety for using cutting-edge technologies aiming not only to increase its productivity and profitability but also to lessen the impact it causes on the environment. In this scenario, Brazil also plays a lead role in global pig production, occupying the forth position in the world ranking of pork production and also of pork exporting, hence, the importance of the pork industry becomes very clear since it is major source of wealth to Brazil's economy, creating thousands of direct and indirect jobs which contribute to socioeconomic development. Thus, it becomes vital to form highly skilled human resources capable of working in an assertive manner on this field, advancing even more the pork industry and, consequently, the development of the country. To attend this demand, the Swine Research Center was created as a result of the merging of three laboratories (Laboratório de Pesquisa em Suínos; Laboratório de Andrologia e Tecnologia de Embriões Suínos; Laboratório de Sanidade Suína e Virologia), with the main objective of permitting that the undergraduate students could have a hands-on experience on the pig production field. Nowadays, undergraduate students can take part on various activities similar to those of a commercial pig farm, always monitored by faculty and post graduate students.
\end{abstract}

Keywords: Pig Production; Human Resources; Interdisciplinary.

\section{Introdução}

O método de ensino ocidental contemporâneo, no qual os docentes assumem papel de transmissores de conteúdos, enquanto o discente os retém e repete numa atitude passiva e receptiva, tem sido muito questionado quanto à sua eficiência. Dessa forma, a busca por alternativas para otimizar os conteúdos, sem mudá-los completamente, deve ser priorizada no método de ensino cartesiano (DESCARTES, [1637] 1996). Nesse contexto, a Faculdade de Medicina Veterinária e Zootecnia da Universidade de São Paulo oferece, por meio 
de um laboratório "modelo" de suínos, a oportunidade para o discente associar o conhecimento compartimentalizado adquirido, aplicando-o no laboratório, que retrata um sistema intensivo de produção de suínos, como forma de treinamento para avaliação dos fatores de risco e, desse modo, de chegar ao diagnóstico de situação. Este modelo permite ao discente propor soluções, executá-las e acompanhar os resultados. O novo método de ensino exige na sua real praticidade conhecimentos técnicos de diversas áreas de atuação do médico veterinário (fisiologia, nutrição, reprodução, sanidade, clínica, entre outras), fazendo com que o aluno reconheça a congruência das informações que vêm sendo passadas de maneira passiva e desenvolva um raciocínio crítico na solução de problemas reais envolvidos na rotina do sistema em questão (PEREIRA, 2003).

\section{História}

No ano de 1995, o projeto de infraestrutura II obteve verba de Auxílio à Pesquisa da Fundação de Amparo à Pesquisa do Estado de São Paulo (1995/4028-7), originando o Laboratório de Pesquisa em Suínos (LPS) pelo então professor titular do Departamento de Nutrição e Produção Animal (VNP) Aníbal de Sant'Anna Moretti, o qual havia muito vislumbrava a formação de um centro de excelência para o desenvolvimento de metodologias experimentais interativas entre as diversas áreas da Medicina Veterinária, Humana e Zootecnia. Segundo o visionário Prof. Dr. Aníbal de Sant'Anna Moretti, o papel da pesquisa acadêmica é gerar novas ferramentas e metodologias para que possam ser aplicadas à rotina de granjas comerciais, contribuindo, dessa forma, para a otimização do sistema de produção de forma global e interativa. Nesse sentido, foram realizados no LPS diversos trabalhos que auxiliaram o aprimoramento da atividade suinícola em nosso país. No entanto, o principal foco do LPS, à época, era a investigação científica direcionada a alunos de pós-graduação, deixando, de certa forma, alunos da graduação desprovidos de um ambiente que lhes permitisse entrar em contato com a rotina de uma granja de suínos comercial; isso porque, finalizados os experimentos, os animais utilizados nos mesmos eram destinados ao abate e as instalações permaneciam vazias, até que outro experimento fosse conduzido no laboratório. Além disso, como os estudos eram modulares (machos reprodutores, gestação, maternidade, creche, crescimento/terminação), a granja não trabalhava em sistema de ciclo completo.

Em 2013 os professores Aníbal de Sant'Anna Moretti, André Furugen Cesar de Andrade e a Dra. Simone Maria Massami Kitamura Martins, objetivando otimizar o uso das instalações do LPS e possibilitar que alunos de pós-graduação e graduação tivessem a oportunidade de entrar em contato com um cenário mais fidedigno da produção de suínos, decidiram por implementar o sistema produtivo de ciclo completo no LPS, sob a organização de produção quinzenal.

Dois anos após o início da implementação do sistema de produção de ciclo completo no LPS, tendo em vista que este apresentava bons resultados e vinha possibilitando a realização de um grande número de experimentos, bem como atraindo cada vez mais alunos, os professores Aníbal de Sant'Anna Moretti e André F. C. de Andrade e a Dra. Simone M. M. K. Martins, juntamente com a Prof ${ }^{\mathrm{a}}$. Dr ${ }^{\mathrm{a}}$. Andrea Micke Moreno, responsável pelo Laboratório de Sanidade Suína e Virologia, pertencente ao Departamento de Medicina Veterinária Preventiva e Saúde Animal (VPS), uniram forças e criaram o Núcleo de Pesquisa em Suínos (NPS) que, desde a sua origem, já recebeu mais de cem alunos, incluindo os de diversos países da América do Sul e Europa, tais como: Inglaterra, Irlanda, Peru, Chile, Colômbia e Espanha; além de alunos de diversas universidades do Brasil que procuram o NPS para a realização de cursos de aperfeiçoamento, atualização, difusão, prática profissionalizante e estágio curricular.

Com relação à Universidade de São Paulo, o NPS, além de naturalmente servir de local para a realização de aulas práticas da disciplina Produção de Suínos, também desempenha importante papel interdisciplinar, servindo como uma grande sala de aula para alunos das disciplinas 
de Bioclimatologia Animal, Programa de Alimentação Animal, Obstetrícia, Biotecnologia da Reprodução, Patologia e Clínica da Reprodução, Introdução à Medicina Veterinária, Introdução ao Estudo da Medicina Veterinária em Sistemas de Criação, Produção e Manejo de Reprodutores Suínos, Clínica Cirúrgica de Grandes Animais, Reprodução Aplicada à Espécie Suína e Anestesiologia e Técnicas de Terapia Intensiva no Paciente Cirúrgico. Ainda nesse sentido, desde a sua formação, sete alunos de graduação desenvolveram projetos de Iniciação Científica, alguns destes com bolsa Fapesp. Os docentes do curso de Medicina Veterinária da Faculdade de Zootecnia e Engenharia de Alimentos também se beneficiam da estrutura ímpar que o NPS oferece, uma vez que algumas aulas de Anestesiologia e Patologia Especial são ali realizadas.

Outro serviço que sempre foi o desejo dos formadores do NPS, e que agora vem sendo prestado à comunidade externa, é o recebimento de visitas de docentes de universidades privadas, os quais não dispõem da mesma estrutura que pode ser encontrada neste. Permite, assim, que esses alunos tenham contato com um sistema de produção de suínos, em geral pela primeira vez. Vale mencionar os docentes da PUC-Minas do Campus Poços de Caldas, que utilizam a visita ao NPS como parte da disciplina Estágio Supervisionado I.

\section{A Granja Experimental}

O Núcleo de Pesquisa em Suínos dispõe das condições necessárias para a realização com exce-

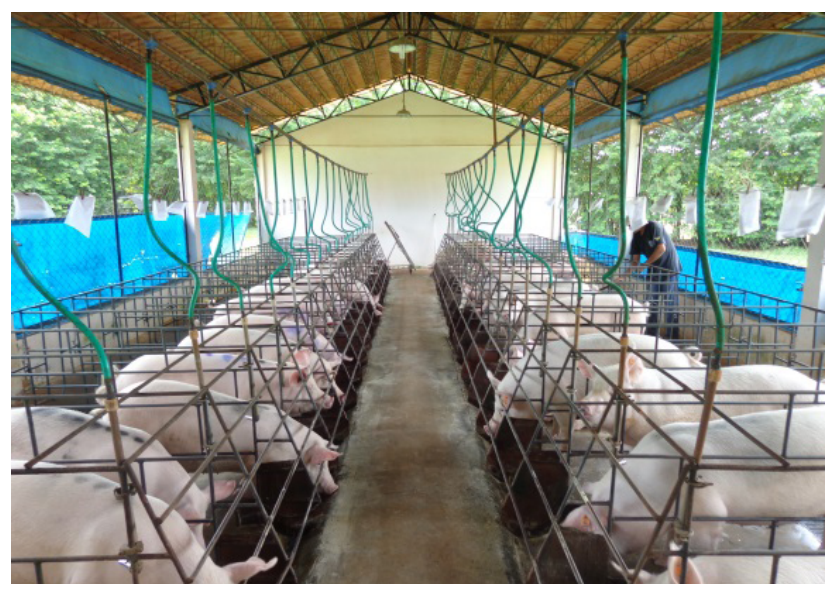

Foto 1 - Sala de gestação. lência de pesquisas e ensino, possuindo as seguintes edificações: duas salas de gestação com gaiolas individuais, sendo 84 no total (Fotos 1 e 2); uma central de colheita de sêmen que permite abrigar seis reprodutores em baias individuais (Foto 3); sala de colheita e laboratório para avaliações avançadas de sêmen (Laboratório de Andrologia e Tecnologia de Embriões Suínos-Lates); instalação de maternidade (Foto 4) dividida em três salas, dispondo assim de 24 gaiolas individuais de parição no total; instalação de creche dividida em três salas com 48 baias no total, capazes de alojar cinco leitões/baia (Foto 5), sendo que as salas possuem lâmpadas infravermelhas para aquecimento dos leitões; unidade de crescimento e terminação, dispondo de três salas com dezesseis baias/sala e capacidade para abrigar cinco leitões por baia (Foto 6)

\section{O NPS/FMVZ/USP como Centro Formador de Profissionais para a Suinocultura: Qual o Perfil que Queremos Formar?}

É unânime entre os profissionais de destaque da suinocultura que o mercado busca pessoas que consigam associar o conhecimento técnico a habilidades de relacionamento interpessoal e liderança cognitiva, apresentando características que supram a necessidade de protagonismo técnico de que o mercado suinícola carece, tais como pró-atividade, responsabilidade, motivação, ética, entre outras. Indo ao encontro disso, sempre fez parte da filosofia do NPS formar esse tipo de profissional tão desejado pelo mercado. Para tanto, a

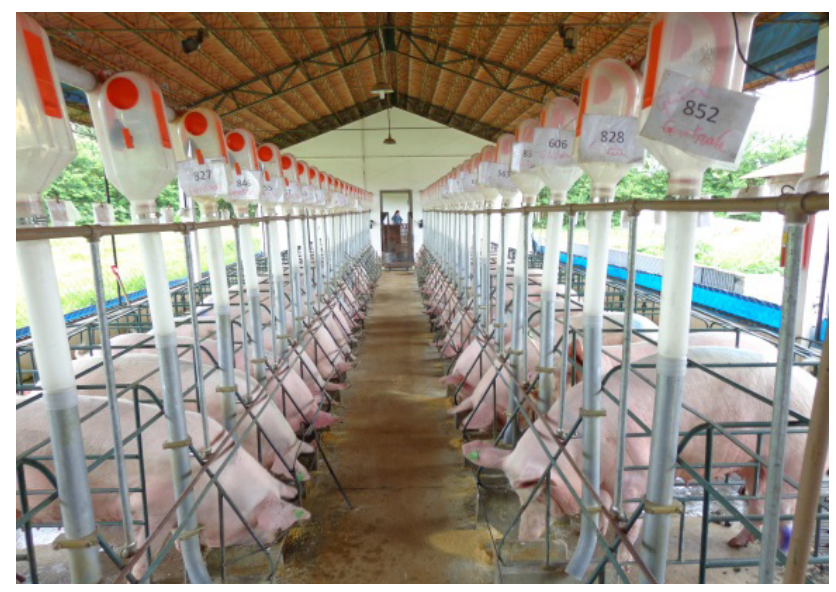

Foto 2 - Sala de gestação. 


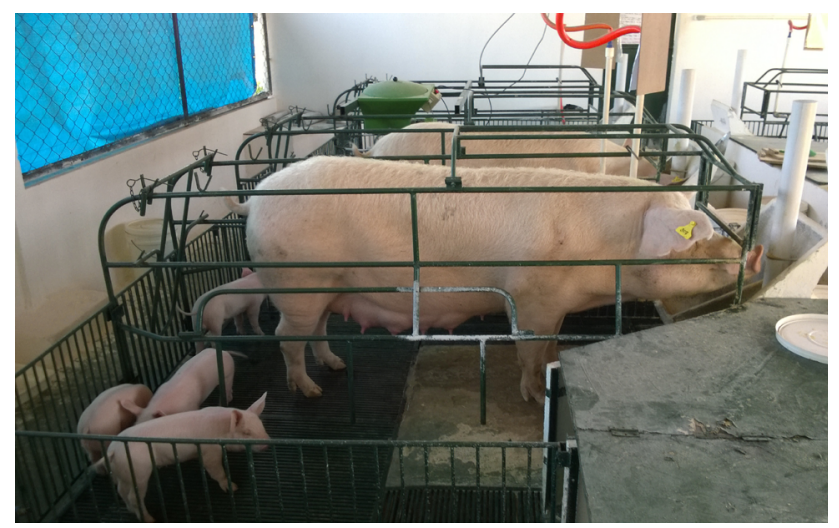

Foto 3 - Central de inseminação.

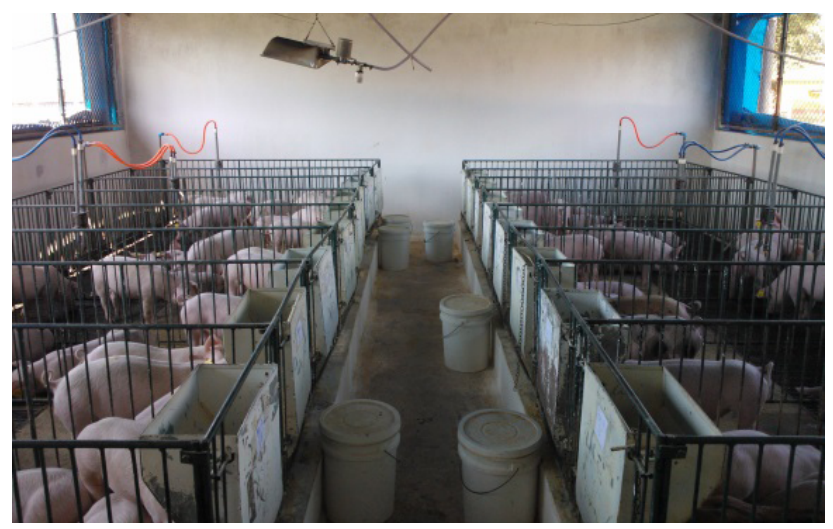

Foto 5 - Sala de creche.

granja experimental do NPS permite que os alunos tenham contato com os desafios enfrentados em uma granja comercial e que, embasados por conhecimento técnico-científico, proponham soluções e melhorias. Os alunos que participam das atividades da granja experimental têm a oportunidade de desenvolver atividades rotineiras que os desafiarão no campo profissional, abrangendo desde a questão reprodutiva (inseminações, colheita de sêmen, avaliação da qualidade espermática, diagnóstico de gestação por ultrassonografia e acompanhamento de partos), até aspectos nutricionais, de manejo e sanitários (formulação de ração, acompanhamento do processo de produção do alimento, higiene das instalações, avaliação de índices produtivos, manejo com animais nas diversas categorias e idades, sinais clínicos e abordagem terapêutica das principais doenças observadas em um sistema produtivo). Além disso, o aluno, ao se deparar com algum problema sanitário no rebanho, pode coletar material e acompanhar o

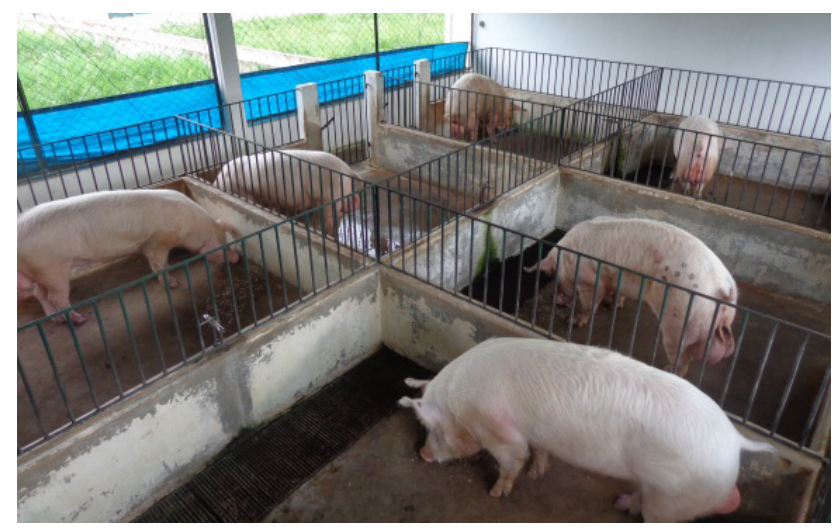

Foto 4 - Sala de maternidade.

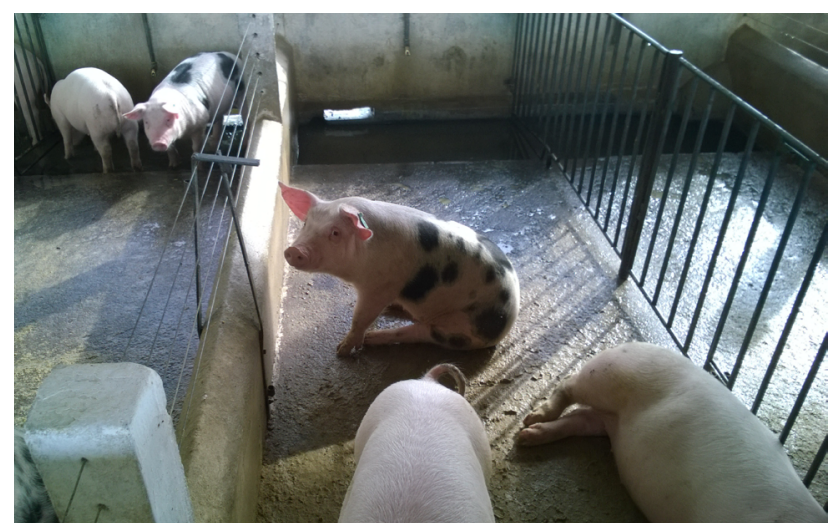

Foto 6 - Sala de crescimento e terminação.

processo de diagnóstico realizado no Laboratório de Sanidade Suína e Virologia, coordenado pela Prof ${ }^{a}$. Dra ${ }^{a}$. Andrea Micke Moreno.

\section{Considerações Finais}

O aluno, ao passar pelo NPS, adquire uma visão holística do sistema de produção suinícola, o que lhe possibilita atuar de forma crítica e assertiva, quebrando assim paradigmas e propondo novas metodologias mais eficientes a serem inseridas no cotidiano de uma granja, o que certamente irá contribuir para a construção da suinocultura do futuro.

\section{Referências Bibliográficas}

DESCARTES, Réne. Discurso do método. Tradução de Maria Ermantina Galvão. São Paulo: Martins Fontes, [1637] 1996, $150 \mathrm{p}$.

PEREIRA, A. P. F. "As Tendências Pedagógicas e a Prática Educativa nas Ciências da Saúde". Caderno de Saúde Pública, vol. 19, pp. 1527-1534, 2003.

Publicado em 22/12/2017. 